\title{
The Ethaline Effect on Feruloyl Esterase Activity ${ }^{\dagger}$
}

\author{
Ioana-Cristina Marinaș ${ }^{1}$, Bogdan Trică ${ }^{1}$, Carmen-Valentina Nicolae ${ }^{1}$, Florin Oancea ${ }^{1,2, *}$ and \\ Diana Constantinescu-Aruxandei ${ }^{1, *}$ \\ 1 The National Institute for Research \& Development in Chemistry and Petrochemistry - ICECHIM, Splaiul \\ Independenței nr. 202 A, 060021 Bucharest, Romania; ioana.cristina.marinas@gmail.com (I.-C.M.); \\ trica.bogdan@gmail.com (B.T.); carmen.nicolae03@gmail.com (C.-V.N.) \\ 2 University of Agronomic Sciences and Veterinary Medicine of Bucharest, Blvd. Mărăști, nr. 59, 011464 \\ Bucharest, Romania \\ * Correspondence: florin.oancea@icechim.ro (F.O.); diana.constantinescu@icechim-rezultate.ro (D.C.-A.) \\ + Presented at the 15th International Symposium "Priorities of Chemistry for a Sustainable Development" \\ PRIOCHEM, Bucharest, Romania, 30th October-1st November 2019.
}

Published: 18 October 2019

Keywords: feruloyl esterase; ferulic acid; solubility; enzymatic activity; 4-nitrophenyl trans-ferulate; ethaline

In recent years, extractions using natural deep eutectic solvents (NADESs) have attracted increasing attention, as these solvents represent an ecological, non-toxic and biodegradable alternative to conventional solvents, being easy to produce in laboratories [1]. Some studies showed that NADESs considerably increased the extractability of phenolic compounds compared to conventional methodology [1,2]. Another green extraction method is the enzymatic one, which can greatly increase the production of phenolic compounds together with other extraction methods [3]. The purpose of this study was to investigate and optimize the activity of feruloyl esterase (FAE) and the solubility of ferulic acid (FA) in ethaline. The FA solubility was tested at different ethaline concentrations $(5 \%-90 \%)$ by the spectrophotometrical method $(\lambda=320 \mathrm{~nm})$. The enzyme activity of FAE was optimized by varying the $\mathrm{pH}$ values, and the substrate (4-nitrophenyl trans-ferulates) and enzyme (feruloyl esterase) concentrations. After optimizing these parameters, the effect of different concentrations of ethaline $(10 \%-45 \%)$ on the enzymatic activity was determined. The optimal $\mathrm{pH}$ value for the reaction was 7 . The enzyme was still active in ethaline, but the initial velocity was decreased at higher ethaline concentrations, probably due to higher viscosity which decreased the diffusion. The solubility of FA decreased with the decrease in ethaline concentration, but it was soluble enough for FA extractions from biomass, even at ethaline concentrations below $50 \%$. In conclusion, FAE can be combined with ethaline at certain concentrations to improve FA extractions from biomass.

Acknowledgments: The work in this paper was supported by Innovative green technologies for valorisation of lignocellulose-INTELIGRENCE (project number: PN-III-P1-1.1-TE-2016-2518) funded by UEFISCDI subordinated to the Ministry of Research and Innovation. We also thank the Government of Romania, Ministry of Research and Innovation for funding the following projects: Enhancing the INCDCP-ICECHIM research and innovation potential within the field of inter-disciplinary and cross-sectoral key-enabling technologies-TRANS-CHEM (project number: PFE 31/2018) and Plant biostimulant based on vegetables extracts-NeXT-STIM (project number: PN.19.23.01.03.).

\section{References}

1. Cunha, S.C.; Fernandes, J.O. Extraction techniques with deep eutectic. Trends Anal. Chem. 2018, 105, 225239. 
2. Dai, Y.; van Spronsen, J.; Witkamp, G.J.; Verpoorte, R.; Choi, Y.H. Natural deep eutectic solvents as new potential media for green technology. Anal. Chim. Acta 2013, 766, 61-68.

3. Azmir J.; Zaidul, I.S.M.; Rahman, M.M.; Sharif, K.M.; Mohamed, A.; Sahena, F.; Jahurul, M.H.A.; Ghafoor, K.; Norulaini, N.A.N.; Omar, A.K.M. Techniques for extraction of bioactive compounds from plant materials: A review. J. Food Eng. 2013, 117, 426-436.

(C) 2019 by the authors. Licensee MDPI, Basel, Switzerland. This article is an open access article distributed under the terms and conditions of the Creative Commons Attribution (CC BY) license (http://creativecommons.org/licenses/by/4.0/). 